DOI 10.37882/2223-2982.2021.12.36

\title{
НЕОЛОГИЗМЫ В ЕВРОПЕЙСКИХ ЯЗЫКАХ (К ВОПРОСУ О ЯЗЫКЕ В ЭПОХУ ПАНДЕМИИ)
}

\section{NEOLOGISMS IN EUROPEAN LANGUAGES (ON THE QUESTION OF LANGUAGE IN THE ERA OF THE PANDEMIC)}

\section{N. Frolova \\ O. Tarasova \\ K. Palekha}

Summary: This study is devoted to the acute problem of the Covid-19 pandemic and its impact on Russian, English, French and German lexicology. Due to the fact that a large number of neologisms associated with coronavirus have appeared, this phenomenon requires a thorough analysis of their structure, semantics and functions, as well as categorization, determination of sources of origin and areas of use.

Keywords: Covid-19, neologism, semantics of lexemes, modern discourse, corpus analysis.
Фролова Наталья Хайдаровна

К.п.н., дочент, Нижегородский Государственный Лингвистический Университет им. Н.А. Добролюбова nfrolova@gmail.com

Тарасова Ольга Михайловна

К.филол.н., доцент, Нижегородский Государственный Лингвистический Университет им. Н.А. Добролюбова, olyatarasova8@rambler.ru

Палеха Ксения Александровна

Преподаватель, Нижегородский Государственный Лингвистический Университет им. Н.А. Добролюбова palehaxenia@gmail.com

Аннотация: Данное исследование посвящено острой проблеме пандемии Covid-19 и ее влиянию на русскую, английскую, французскую и немецкую лексикологию. В связи с тем, что появилось большое количество неологизмов, связанных с коронавирусом, это явление требует тщательного анализа их структуры, семантики и функций, а также категоризации, определения источников происхождения и областей использования.

Ключевые слова: Covid-19, неологизм, семантика лексем, современный дискурс, корпусный анализ.

мнения студентов и анализ публикаций СМИ на иностранных языках. Для решения поставленных задач были использованы следующие методы исследования: контент-анализ, метод косвенного наблюдения, методы качественного и количественного анализа, сравнительный метод и метод обобщения полученных результатов.

\section{Результаты} факт, что этот вопрос малоизучен в отечественной и зарубежной лингвистике

\section{Шель исследования}

Цель данного исследования состоит в том, чтобы исследовать специфику образования неологизмов периода пандемии COVID-19 2020-2021годы, изучить существующие неологизмы путем анализа публикаций в СМИ Германии, Франции и Америки. Данная работа посвящена подготовительному этапу по созданию словаря неологизмов в европейских языках

\section{Методология (материалы и методы)}

Выбор методологической основы данного исследования является проявлением научной мировоззренческой позиции данной группы авторов, которая состоит в использовании современных научных подходов в рамках лингвистических исследований. Для работы были использованы следующие способы получения данных: проведение опроса для получения непосредственного
В рамках исследования были получены следующие теоретические и экспериментальные результаты: неологизмы отражают активные процессы современного словопроизводства. В связи с пандемией COVID-19 словарный запас русского языка стремительно пополнился и продолжает пополняться новыми словами во всех европейских языках

2020 год - это начало тревожного и затяжного этапа для всего мира, начало страшной эпидемии нового вируса, до того дня неизвестного учёным. 11 февраля 2020 г. Всемирная организация здравоохранения присвоила официальное название инфекции, вызванной новым коронавирусом, - COVID-19 ("CoronaVIrus Disease 2019"). Столкнувшись с пандемией, представители научного мира 21 века начали искать обозначения предметам, действиям, признакам, появившимся в связи с COVID-19. Новая лексика пандемии коронавируса становится ярким отражением процесса образования неологизмов во всех языках [2]. Французы подхватили название, и ко- 
нечная буква S произносится Coronavirus-c'est le virus à couronne qui doit son nom à l'apparence des virions sous un microscope électronique, avec une frange de grandes projections bulbeuses qui ressemblent à la couronne solaire.

COVID-редуцированная форма от CoV (du latin, virus à couronne) Pandémie c'est une épidémie qiui désigne un grand nombre de cas d'une maladie, infectieuse, dans une région donnée. Distanciation sociale ce sont les gestes barrières, la population est invitée à la distanciation sociale, à savoir rester à distance d'autrui pour diminuer les risques de contagion.

Французское слово "quarantaine" слово используется в юридической терминологии. По закону "четырнадцатый" являет собой "14-дневный промежуток, который юридически соблюдался между различными этапами судебного ареста". По образцу слова "карантин", которое обозначало 40-дневную изоляцию людей, подозреваемых в переносе чумы. Рассмотрим примеры со словом «cas», количество употреблений в СМИ заметно увеличилось:

cas confirmé - подтверждённый случай,

les cas diagnostiqués - диагностированные случаи,

les cas asymptomatiques - бессимптомные случаи.

\section{Как дополнение}

la fermeture des restaurants et des bars - закрытие peсторанов и баров,

la fermeture de frontière - закрытие границ,

les nouvelles restrictions - новые ограничения,

un prolongement des mesures restrictives - продление ограничительных мер,

la propagation du virus - распространение вируса,

la vitesse de propagation - скорость распространения, ralentir / freiner la propagation - замедлить / затормозить распространение,

le couvre-feu - комендантский час,

instaurer le couvre-feu - установить комендантский час.

В последние годы наблюдается растущий интерес научного сообщества к корпусным исследованиям, в которых наблюдаются заимствования в русской и английской лексике. Появление новых лексем в период пандемий привлекает внимание лингвистов и психологов. Актуальность и вклад исследования были повышены за счет установления межъязыковых связей между семантическими особенностями лексемы коронавирус в двух наиболее распространенных языках (русском и английском). Эмпирически можно сравнить лексемы, семантически связанные с Covid-19 в L1 и FL.

pandemic - пандемия, coronavirus outbreak - вспышка коронавируса

Coronic-заболевший, the world is dealing with pandemic - мы имеем дело с пандемией, to slow the spread of transmission of the virus - замедлить распространение вируса, maskhole- противник ношения масок

have been exposed to coronavirus - быть подверженным вирусу

be most at risk - подвергаться наибольшему риску

coronials-рожденные в эпоху пандемии, ability to fight the virus - способность бороться с вирусом

spread the virus to other people - передавать вирус другим людям

Следует отметить две основные ситуации, в которых использование неологизмов релевантно. Очевидна негативная коннотация значения неологизма в первой ситуации и некая положительная оценка во второй.

Covidiot Неологизм covidiot (допускаются также написания COVIDiot/Covidiot) является существительным (noun) и образовано при помощи контаминации - соединения двух полных основ с междусловным наложением (гаплология): covidiot $\leftarrow$ covid (noun) (или COVID наименование вируса) + idiot (noun) - a stupid person or someone who is behaving in a stupid way. Примеры употребления: "But none of the words can compare to the impact "coronavirus" had on the English language starting in March. The word quickly became one of the most frequently used nouns in the English language and led to completely new words and abbreviations, such as "COVID," "COVID-19," "rona," "covidiot" and others." (Coronavirus Corpus).

them with hand sanitizer every two or three minutes. \#Covidiot" (Twitter).

В примере из социальной сети видна препозиция неологизма перед другим существительным (protesters), что ставит под сомнение статус слова covidiot как существительного (возможная конверсия в прилагательное). Действительно, эта точка зрения достаточно распространена в лингвистике, однако существует противоположное мнение - такие слова остаются существительными (их называют attributive nouns), и поскольку это довольно дискуссионная тема в языкознании, было принято решение считать слова в таких случаях существительными для возможности определения более точного контекста и коммуникативных ситуаций употребления неологизмов.

Неологизм Moronavirus является синонимом слова covidiot и обладает таким же определением и набором ситуаций (различий в употреблении выявлено не было). В качестве примера приведем статью с Urban Dictionary: "Moronavirus patient \#1: How dare you step outside your house. We need to keep locked down until we find a vaccine. Response: Really? Do you realize over $25 \%$ of the population.

Различием двух синонимов является частота использования: covidiot более популярно, последнее его 
использование датируется 12.03.2021 (по результатам поиска в корпусе), в то время как частота использования moronavirus намного ниже и последнее его появление было зафиксировано 25.04.2020. Дефиниция представлена следующим образом: “Quarantini (noun [countable]) - a cocktail that you drink while in quarantine, made from whatever ingredients are available to you". Проанализировав различные контексты употребления слова quarantini в корпусах и социальной сети Твиттер, мы пришли к выводу, что приведенное выше определение является полным и на данном этапе не нуждается в дополнении. Однако следует отметить, что в процессе лексикализации произошло расширение семантического значения, т.к. изначально quarantini являлся коктейлем, приготовленным из мартини с добавлением пищевых добавок на основе витамина С. На текущий момент оно подразумевает любой алкогольный напиток, сделанный дома в период вынужденной изоляции. Из примеров можно судить о довольно разнообразных вариантах использования неологизма Coronaphobia is среди пользователей Твиттера: контексты позволяют установить, что люди могут не только причислять себя к обладателям такой фобии, но еще и достаточно пренебрежительно к ней относиться, с некоторой долей иронии или даже цинизма.

"Coronaphobia is an excessive triggered response of fear of contracting the virus causing COVID-19, leading to accompanied excessive concern over physiological symptoms, significant stress about personal and occupational loss, increased reassurance and safety seeking behaviors, and avoidance of public places and situations, causing marked impairment in daily life functioning."(https:// www.ncbi.nlm.nih.gov/pmc/articles/PMC7474809/).

Как можно заметить, оно довольно громоздко и включает в себя множество медицинских терминов, а также не содержит информации о том, что человек с таким страхом боится не только за себя, но и за близких ему людей и/или родственников, поэтому нам кажется возможным дать такое определение:

"Coronaphobia is a type of anxiety which is caused by fear of catching the virus yourself or worries that loved ones will get sick, which leads to significant stress, safety seeking behaviors, and avoidance of public places and situations."

Неологизм Coronacoaster является существительным (noun), образованным при помощи контаминации - соединения полной основы одного исходного слова с усеченной основой другого без наложения фонем: coronacoaster $\leftarrow$ corona + rollercoaster/ "The very challenging mix of emotions brought on by the coronavirus pandemic this year has been termed the' coronacoaster' and the psychologists have designed the course to address those feelings." (Coronavirus Corpus).
"But even they are not immune to the ravages of Covid-19 and the crisis in which the industry finds itself. Ninety-two days of lockdown and counting, and the hospitality industry is still riding the coronacoaster of stomach-churning loops and somersaults. It's hard enough to be in this business even at the best of times, but the past few weeks -- which, frankly, feel like months -- have seen valiant struggles as restaurants and coffee shops have done everything in their power to keep going, only to admit defeat and announce they are closing their doors for good" (Coronavirus Corpus). Итак, очевидно использование coronacoaster в рамках формального регистра (помимо обозначения некоторого психологического состояния в научных и околонаучных статьях зафиксировано употребление неологизма в новостях и заметках о состоянии экономики в мире, что также можно отнести к формальному регистру), в то же время широко распространение слова в неформальном регистре (для обозначения эмоций пользователя, опубликовавшего пост).

Рассмотрим Covidian Данный неологизм (возможны следующие написания: covidian, Covidian, COVIDian) является существительным (noun), полученным от слова covid (обозначающем название вируса, вызвавшего пандемию) путем аффиксации - присоединением суффикса -(i)an, который указывает на специализацию, национальность или вероисповедание человека, т.е. на принадлежность к чему-либо. Кроме того, covidian получило свое распространение и как прилагательное (adjective), что свидетельствует о конверсии (в данном случае: переход из существительного в прилагательное $\mathrm{N} \rightarrow \mathrm{Adj}$ ). "New Zealand's exports have actually grown 1\% since the beginning of the Covidian era" (Coronavirus Corpus) "Having had some delays, which are Covidian and otherwise, we are now on course to occupy the building in this first quarter of calendar year 2021, " the Minister said." (NOW Corpus).

В примерах публикаций из Интернет-СМИ очевидно "нейтральное" значение неологизма, обозначающего некую "принадлежность" к времени коронавируса: например, Covidian era - время (эра) коронавируса, т. е. какоето явление, происходящее в этот период. В то же время, в социальной сети Twitter пользователи используют эту новую лексическую единицу совершенно для других реалий - так называют людей, придерживающихся так называемого коронавирусного "культа".

Примечательно, что широкое распространение в социальных сетях получило словосочетание branch covidians. Оно является калькой с названия тоталитарной деструктивной секты Branch Davidians, существующей на территории США с 1955 года и известной по трагической двухмесячной осаде особняка, в результате которой погибли 76 человек.

Coronababy неологизм (возможен также вариант во множественном числе: coronababies) является существи- 
тельным (noun), образованным контаминацией полной основы одного исходного слова с усеченной основой другого без наложения фонем: coronababy $\leftarrow$ coronavirus (название вируса) + baby (a very young child, especially one that has not yet begun to walk or talk).

"The news follows speculation that life in lockdown could lead to a baby boom in nine months' time, with a wave of so-called "coronababies " being born around Christmas." (Coronavirus Corpus) "Previously, experts had predicted that the March 2020 lockdown would lead to a wave of socalled' coronababies', but this has not occurred at a great scale." (NOW Corpus)

В данном анализе рассматриваются примеры из корпусов именно на множественном числе вследствие специфичности употребления единственного числа: вопервых, оно малочисленно, во-вторых, оно применяется как термин или слово, которое появилось в период карантина, следовательно, получить контексты для понимания регистров, коммуникативных ситуаций и определения следует, опираясь на использование множественной формы неологизма coronababy - coronababies.

На основе примеров можно сделать вывод: неологизм используется в формальном регистре, близком к нейтральному (т. е. больший уклон именно к нему), поскольку он употребляется в официальных СМИ в Интернете, однако их тексты близки к нейтральному регистру для большей степени понятности и доступности. [1]. Не только революционные открытия в науке и технике, исторические события и новые достижения требуют новых номинаций. Германия, как и все страны Европы, столкнулась с новым глобальным явлением, которое потребовало безотлагательных политических и социальных решений. Пандемия новой коронавирусной инфекции, начавшаяся в 2019 году в Азии и окрестившая собой весь 2020 год, внесла существенные изменения в жизнь всего мира. И такие коррективы не могли не отразиться в языке. В данной статье рассматриваются некоторые неологизмы немецкого языка, появление которых вызвано пандемией COVID-19. Один из самых популярных словарей немецкого языка Duden выпустил новое издание, в которое включил целый перечень общеупотребляемых немецких слов, которые за последние почти 2 года прочно вошли в повседневный дискурс. Интересно отметить, что только по запросу Covid-19 данный источник [6] выдает 16 новых лексических единиц, ранее не употреблявшихся.

Одно лишь слово "Corona" вызвало к жизни множество производных слов и словосочетаний, которые прочно укрепились в лексиконе немцев. Новые лексические единицы имеют внеплановое обновление среди слов, связанных с пандемией и локдауном, болезнью и различными реакциями на нее. Ведь именно словообразование, «используя морфемный инвентарь языка, вы- полняет заказ общества на создание необходимых для коммуникации наименований» [7]. Такую лексику можно назвать маркерами современности, которые могут быть представлены в виде слов, словосочетаний, иногда предложений, являясь приметами определенного периода истории.

Вместе с самоизоляций, вызванной пандемией, и другими ограничениями в словарном запасе немцев прочно укрепились такие слова, как «zoomen» [4]. Хотя онлайн-видеоконференции привнесли в нашу жизнь новые возможности, впечатления, способы поведения и новый рабочий и учебный график, общение с коллегами и одногруппниками только через экран компьютера, повлияло на изменение состояния здоровья человека. Говоря о самоизоляции, нельзя не отметить новую лексическую единицу немецкого языка «overzoomed» («передозировка» Zoom, стресс от чрезмерного использования данной платформой).

«Corona-Babys» (новое поколение детей, которое прогнозируют ученые после начала карантина «Lockdown»). Немецкие старшеклассники сдают «Corona-Abitur» («корона-экзамен», экзамен для получения аттестата зрелости). Из-за невозможности посетить парикмахерскую или салон красоты, в лексикон немцев вошло слово «Coronafrisur» («коронная прическа», прическа или стрижка в условиях самоизоляции).

Некоторые неологизмы обозначают бытовые моменты после объявления локдауна. Например, в словарный запас немцев вошли такие лексические единицы как «Balkonsingen» (балконное пение), «Balkongesang» (пение на балконе), «Balkonsänger» («балконный исполнитель»). Эти слова также отображают современные реалии, когда людям просто хочется отдохнуть, и они устраивают концерты с музыкой и пением на балконе для соседей [4].

Интересно обратить внимание на слова руководителя Института немецкого языка им. Лейбница (IDS) Хеннинга Лобина в интервью газете Süddeutsche Zeitung. Он следующим образом описал активное появление новых лексических образований, появившихся в разгар пандемии Covid-19: «Solche Wörter sind unser Brot- undButtergeschäf» (пер. Такие слова для нас хлеб насущный)/ По мнению данного эксперта, заслуживает внимания такая словообразовательная модель, как «Coronoia», дающая отсылку к слову «Paranoia» (паранойя) [5].

Die Panikdemie [3] (эпидемия паники) -из лексемы die Epidemie (эпидемия) заимствована последняя часть слова для образования неологизма. Также получил распространение такой термин, как Aluminiumhut (алюминиевая шапка, шапочка из фольги). Данной лексической единицей обозначают сторонников теории заговора, в том числе по отношению к появлению и развитию новой 
коронавирусной инфекции.

Действительно, с развитием современных информационных технологий, СМИ, активным использование социальных сетей современным обществом значительную популярность приобретают электронные версии изданий, аккаунты Instahramm и Telegramm, связанные непосредственно с темой пандемии. Все это превращает журналы, газеты, другие издания в источник новейших словообразований, так как они отражают самые актуальные новости, вопросы и проблемы и способствуют их быстрому распространению.

Стоит также подчеркнуть, что лексика пандемии COVID-19 находит свое отражение в таких лингвистических рейтингах Германии, как «Wort des Jahres» и "Jugendwort des Jahres», так как неологизмы отражают не только такую мировую реалию как коронавирус, но и устанавливают соответствующее отношение общества к нему.

\section{Выводы}

Несмотря на то, что лишь небольшое количество лексем обладает потенциалом дальнейшего закрепления в структуре европейских языков у исследователей вызывает огромный интерес именно количество неологиз- мов, и сопряженные с этим процессы адаптации, освоения лексем, формирования полисемии и омонимии. На лицо тот факт, что течение одного года новые языковые единицы претерпели ряд изменений, которые обычно становятся результатом довольно долгого процесса ассимиляции в языке [3]. Таким образом, основной состав лексики пандемии коронавируса в европейских языках (французский, английский, немецкий) составляют новые слова, и даже целые выражения, относящиеся к непрофессиональному медицинскому дискурсу. Большинство неологизмов представляют собой контаминативные образования. «Контаминация - взаимодействие, скрещивание, объединение языковых единиц или их частей на основе их структурной, функциональной или ассоциативной близости, приводящее к их семантическому или формальному изменению, а также к образованию новой языковой единицы [2].

Современные преобразования в обществе и резкая глобальная изоляция требуют устранения пробелов в академических исследованиях, в которых рассматриваются только медицинские термины эпохи Covid-19, в основном за пределами их общей семантики. Необходимо исследовать причины появления новых лексических единиц, связанных с Covid-19 в современном дискурсе, и изучить реальные случаи.

\section{ЛИТЕРАТУРА}

1. Фролов С.В., Фролова Н.Х. Национальная Самоиндентификация как социокультурный и правовой инструмент формирования патриотизма в Кн Феномен патриотизма в трансструктурном коммуникационном поле-Нижний Новгород, 2020 С. 264-267

2. Григорьев В.А. Свойства цивилизационных маркеров // Словосочетание и предложение в языках разных типов. Межвузовский сборник научных трудов. Пятигорск, 2009.

3. Земская Е.А. Активные процессы современного словопроизводства // Русский язык конца XX столетия (1985-1995). - М., 1996. - С. $90-141$.

4. Allgauer-Zeitung. Covidiot oder Simp. [Электронный ресурc]. URL: https://www.allgaeuer-zeitung.de/welt/panorama/covidiot-oder-simp-abstimmung-zumjugendwort-des-jahres-2020_arid-219051

5. Duden Wörterbuch [Электронный ресурс]. URL: https://www.duden.de/suchen/dudenonline/Covid-19

6. IDS, Neuer Wortschatz rund um die Coronapandemie, 2021. [Электронный ресурc]. URL: https://www.owid.de/docs/neo/listen/corona.jsp

7. Ильясов Р. Короноик и карантинка. Какие новые слова появились из-за COVID-19? //Вопросы Интернет-образования. 07.07.2020. — https://tengrinews.kz (декабрь, 2020).

( Фролова Наталья Хайдаровна (nfrolova@gmail.com), Тарасова Ольга Михайловна (olyatarasova8@rambler.ru), Палеха Ксения Александровна (palehaxenia@gmail.com).

Журнал «Современная наука: актуальные проблемы теории и практики» 